\title{
La comida del otro: el papel del régimen alimenticio en la formación de identidad $y$ alteridad entre los mayas lacandones
}

Alice Balsanelli- Escuela Nacional de Antropología e Historia ${ }^{1}$

DOI: https://doi.org/10.5565/rev/periferia.614

\begin{abstract}
Resumen
El presente artículo analiza la relación entre la construcción de la identidad, la alteridad y el régimen alimentario en un sistema animista. Se tomó en cuenta un caso etnográfico concreto, estudiado en el transcurso de un largo trabajo de campo entre los mayas lacandones de la Selva Lacandona (Estado de Chiapas, México). Se postula que, en un sistema en el cual todos los existentes son dotados de alma y otorgados de condición de persona, la alimentación, perteneciente al ámbito de lo corporal, se vuelve un importante referente para definir las fronteras ontológicas y diferenciar una humanidad específica y etnocéntrica (el grupo indígena de referencia) de una "humanidad" generalizada.
\end{abstract}

Palabras clave: mayas lacandones, animismo, régimen alimenticio, corporalidad, identidad, alteridad.

Abstract. The food of the other: the role of diet in the formation of identity and alterity among the Lacandon Mayas

The aim in this article is to analyze the relationship between feeding and alterity inside an animistic system. A specific ethnographic case will be taken into account, studied among the Lacandon Mayas in the Lacandon Jungle (Chiapas, México), through an extended fieldwork. We infer that, in a system in which all beings of the cosmos are endowed with a soul and personhood, diet -which belongs to the dimension of corporality- becomes the main reference for setting ontological boundaries, as it allows the separation of a specific and ethnocentric humanity (the indigenous reference group) from a generalized "humanity".

Keywords: Mayas, Lacandons, animism, diet, corporality, identity, alterity.

\section{Sobre el proceder metodológico}

El presente artículo forma parte de mi investigación doctoral, que consistió en aclarar las concepciones de persona y de alteridad entre los mayas lacandones de la Selva Lacandona (Estado de Chiapas, México). Este pequeño grupo étnico, que

\footnotetext{
${ }^{1}$ Enviar correspondencia a: Alice Balsanelli, lalacandona@hotmail.it
} 
Alice Balsanelli, La comida del otro: el papel del régimen alimenticio en la formación de identidad y alteridad entre los mayas lacandones, perifèria 22(2), diciembre 2017

\section{revistes.uab.cat/periferia}

cuenta con cerca de novecientos miembros, ha suscitado el interés de antropólogos de todo el mundo, debido a que su comportamiento ritual manifiesta fuertes correspondencias con las prácticas de los mayas prehispánicos. Por consiguiente, se enfocaron los trabajos en la búsqueda de aquellos rasgos culturales que permitían establecer conexiones entre los lacandones y sus ilustres ancestros: el sistema ritual, el panteón prehispánico, la veneración de los antiguos centros ceremoniales (Palenque, Yaxchilán y Bonampak). Dicha actitud se inserta en el marco de una antropología de rescate, y ha llevado a lo que Trench (2005) define "inercia etnográfica". Por ello, mi primer cometido fue la búsqueda de temáticas inéditas, no mencionadas en etnografías precedentes. Entre ellas, encontramos la noción de persona y de alteridad, además del estudio de la relación existente entre la clasificación taxonómica y el régimen alimentario. Lo anterior pudo lograrse rescatando la importancia del trabajo de campo, que permitió el acercamiento a los sujetos de estudio, así como el aprendizaje del idioma local y la recopilación de datos novedosos. Se recurrió a las técnicas etnográficas clásicas: largas estancias en campo en las comunidades de Najá y Metzabok (desde 2012 hasta 2017) y a la observación participante. Asimismo, se cruzaron y sustentaron los datos recabados en campo con la información presente en el corpus literario inherente a otros grupos mayances, con fines comparativos.

\section{Pregunta de investigación e hipótesis}

Se parte de la consideración que los lacandones se caracterizan por una ontología animista: un sistema en el cual cada existente del cosmos es dotado de una interioridad idéntica a la del hombre; por consiguiente, a primera vista nada permitiría distinguir al ser humano de los demás existentes, todos otorgados de alma y de condición de persona. Si todos los existentes se distribuyen en colectivos sociales y se consideran winik (gente) al interior de ellos, ¿en qué manera el ser humano se diferencia de las demás subjetividades? Se postuló que una de las principales discriminantes ontológicas es la alimentación, que caracteriza los distintos seres del cosmos y permite su organización en categorías. 
Alice Balsanelli, La comida del otro: el papel del régimen alimenticio en la formación de identidad y alteridad entre los mayas lacandones, perifèria 22(2), diciembre 2017

revistes.uab.cat/periferia

El trabajo que proponemos se presenta en cinco apartados, en los que se abordarán las siguientes temáticas: 1- introducción al problema de estudio, 2- la alimentación como factor de distinción étnica, 3- el régimen alimenticio de las deidades; 4- la comida como vector de cambio ontológico, 5- la alimentación de las deidades ctónicas y de los difuntos.

\section{Elementos teóricos}

La Antropología Amazónica, que se ha desarrollado en los últimos años, constituye una verdadera revolución teórica, en cuanto que propone una nueva manera de interpretar a la cultura de los nativos. Si bien los exponentes de esta corriente de pensamiento difieren en distintos puntos teóricos, podemos encontrar unas tendencias comunes. En primer lugar, el núcleo central del "giro ontológico" se funda en la negación de las dicotomías occidentales sobre las cuales la Antropología ha definido su objeto de estudio: naturaleza y cultura, cuerpo y alma, individuo y sociedad, natural y sobrenatural. Estos dualismos están ausentes en las concepciones indígenas, y no encuentran ninguna correspondencia en las lenguas nativas. Asimismo, sus exponentes (Viveiros de Castro 2010; Descola 2012; Fausto 2002; Vilaça 2012, Airhem 2010, entre otros) explican de manera inédita que las sociedades indígenas no poseen una noción de persona ( $y$ alteridad) correspondiente a la idea occidental: la condición de humanidad se extiende a un conjunto de seres (animales, plantas, objetos inertes, espíritus) que, de acuerdo con los nativos, son personas. Es la primera vez que la Antropología toma en cuenta entidades extra-humanas en el estudio de una idea de persona.

Los estudiosos de animismo apuntan a que, en un sistema en el que todos los existentes comparten la misma interioridad y son susceptibles de ser "persona", el cuerpo se convierte en el punto de partida de toda clasificación ontológica y el referente central de las relaciones inter-específicas. Sin embargo, al hablar de cuerpo no se hace referencia únicamente al organismo, sino a todas aquellas prácticas que a ello se conectan y que permiten su construcción y su existencia al interior de la sociedad y del cosmos. En este sentido, la alimentación constituye 
Alice Balsanelli, La comida del otro: el papel del régimen alimenticio en la formación de identidad y alteridad entre los mayas lacandones, perifèria 22(2), diciembre 2017

\section{revistes.uab.cat/periferia}

uno de los factores centrales que permiten la construcción del yo (del sujeto social) y su separación de un sinnúmero de entes dotados de alma. A juicio de Viveiros de Castro (2010), el factor de diferenciación ontológica no es la comida per se, sino el cuerpo que mira la comida: cuerpos distintos, mirando al mismo objeto, ven cosas distintas. De acuerdo con Descola, esta concepción se vincula con la idea de una condición de persona extendida a todos los seres del cosmos, que comparten con el ser humano una cultura, y menciona el caso etnográfico wari':

Los waris suponen que el pecarí hace cerveza de maíz y que el jaguar lleva la presa a su casa para que su esposa la cocine, pero saben bien que el jaguar devora a su presa cruda y que el pecarí devasta las plantaciones de maíz en vez de cultivarlas. Son el jaguar y el pecarí, dicen, los que se perciben a sí mismos como si realizaran gestos idénticos a los de los humanos y se imaginan de buena fe que comparten con estos el mismo sistema técnico, la misma existencia social, las mismas creencias y aspiraciones (2012:204).

Todos los seres del cosmos animista están imbuidos en un sistema en el cual las fronteras ontológicas, los cuerpos, los lazos de parentesco y la condición de humanidad deben ser constantemente construidos, reafirmados y estabilizados. Es interesante notar, como lo evidenció Vilaça (2016), que el hecho de que un padre y una madre sean humanos no garantiza que el producto de su unión pertenezca a la misma especie: a menudo, el niño es concebido como "otra cosa" (un pez, un ave, un mono) y debe ser convertido en humano a través de ciertas prácticas que tienen la finalidad de moldear su cuerpo: la alimentación, el cariño materno y la enseñanza del idioma. Un singular caso etnográfico reportado por Grotti y Brightman permite aclarar que la condición de humanidad es el resultado de un proceso de construcción, en el que la alimentación adquiere una profunda significación. Entre los indios trio, los perros de cacería son asociados a personas salvajes: deben ser educados desde pequeños y sus cuerpos necesitan ser "moldeados" (moulded). Las mujeres ancianas se encargan de su crianza, los alimentan con comida humana y se refieren a ellos utilizando el término jimuku, "mi hijo" (2012:164). Vemos cómo un animal puede ser incluido en el grupo 
Alice Balsanelli, La comida del otro: el papel del régimen alimenticio en la formación de identidad y alteridad entre los mayas lacandones, perifèria 22(2), diciembre 2017

\section{revistes.uab.cat/periferia}

familiar y convertido en pariente a través de la educación y la alimentación. Asimismo, la comensalidad juega un papel fundamental en la creación de los lazos de parentesco, como es mencionado en el trabajo de Vilaça (2016), que utiliza la expresión "Making kin out of others". El acto de compartir comida permite generar o fortalecer los lazos de parentesco, que habilitan la reproducción del grupo, al generar un mismo cuerpo entre sus integrantes. Como lo apunta Fausto, comer como el otro o con el otro es un fuerte vector de identidad, implicando un proceso de transformación que lleva a la identificación con la otredad (2002: 15).

Sobre la base de estas consideraciones, analizaremos los distintos regímenes alimenticios de las alteridades lacandonas.

\section{Comer como un Hombre Legítimo}

En la sociedad occidental, la alteridad se concibe en términos de diferencia de culturas; cada grupo humano evidencia determinadas características culturales para identificarse y diferenciarse de los demás grupos. En este sentido, la alimentación constituye uno de los principales factores de definición étnica, como bien lo apunta Fischler:

Los hombres marcan su pertenencia a una cultura o a un grupo cualquiera por la afirmación de su especificidad alimentaria o, lo que es lo mismo, por la definición de la alteridad, de la diferencia frente a los otros [...] En el interior de una misma cultura un grupo define muy frecuentemente al grupo vecino como «comedores de...» (1995: 68).

El recurso del régimen alimentario como parámetro de identificación está presente en todas las culturas del mundo y las sociedades indígenas no constituyen una excepción; los mayas tienden a autodefinirse "hombres legítimos", para distinguirse de la alteridad humana "no auténtica" que se caracteriza por diferentes costumbres. Los mayas tzeltales de Chiapas se definen bats'il winik "los hombres verdaderos", un término que se opone a kaxlan, "castellano", con el que se denomina a los mestizos. Los tojolabales se llaman a sí mismos tojol winik'otik: "el 
Alice Balsanelli, La comida del otro: el papel del régimen alimenticio en la formación de identidad y alteridad entre los mayas lacandones, perifèria 22(2), diciembre 2017

\section{revistes.uab.cat/periferia}

pueblo de la palabra legítima", de tojol, "legítimo o verdadero" y ab'al, "palabra" (Ruz 1981). Asimismo, los qu'eqchís guatemaltecos se autodefinen tzakal winq o yal winq "hombres auténticos" (Estrada 2006). Los mayas choles se definen como "milperos" (del término chol, "milpa"), no se identifican como "hombres verdaderos"; sin embargo, el término indica que los miembros de este grupo son los que producen y comen maíz, diferenciándose de "los extranjeros", que se caracterizan por distintas labores y alimentaciones (Morales 1984: 116). En todos los grupos, el consumo de maíz y las actividades que se conectan a esta planta son un emblema de distinción cultural.

Los lacandones se autodefinen Jach Winik, "Hombres Auténticos" y cuando los informantes son llamados a definir su etnicidad, recurren a los rasgos fundamentales de su cultura: la vestimenta tradicional masculina (túnica blanca de algodón y cabello largo y suelto), el idioma, llamado jach tan (la verdadera lengua), la religión (el culto pagano a los dioses y los ritos asociados a ello) y, sobre todo, el tipo de alimentación: «Somos Jach Winik porque tenemos a nuestros dioses, porque trabajamos en la milpa y comemos el maíz. Somos pobres, pero no nos falta nada. El hombre debe de tener túnica y cabello largo y trabajar siempre. Somos maya» (Najbor, informante).

Los lacandones llaman a su comida jach yochi (verdadera comida): se trata del maíz, elemento fundamental de su dieta y cosmovisión, y de todos los productos cultivados en la milpa o recolectados en la selva: frijoles, calabazas, vegetales silvestres, carne de cacería. Se distinguen de los demás grupos humanos que se "alimentan de otras cosas" y esta diferencia es establecida en el mito, en el cual se especifica que el Creador de los lacandones, Hachäkyum, otorgó a sus hijos el precioso grano y todas las herramientas para cultivarlo y prepararlo, mientras que Äkyantho', dios de los "blancos", creó el dinero, las tiendas y las fábricas, para que sus criaturas pudieran producir su alimento, venderlo y comprarlo (Bruce 1974).

2 Parcela sembrada. Es una antigua técnica mesoamericana de cultivo, cuyo eje se fundamenta en la siembra de maíz, frijol y calabaza. 
Alice Balsanelli, La comida del otro: el papel del régimen alimenticio en la formación de identidad y alteridad entre los mayas lacandones, perifèria 22(2), diciembre 2017

\section{revistes.uab.cat/periferia}

\section{La comida de los dioses}

A pesar de los cambios culturales impulsados por los repetidos intentos de conversión (Boremanse 1998), los lacandones han conservado el panteón prehispánico, que incluye un gran número de deidades principales y menores, cada una asociada a una función específica. De acuerdo con la escatología lacandona, los dioses protagonizan un mito de génesis parecido al que relata la creación de los humanos: ellos fueron creados por una deidad remota, K'akoch, llamado "el dios de los dioses", el cual no es venerado por los lacandones. Empero, las deidades lo reconocen como su Creador y le rinden culto, oficiando ceremonias en su honor y proporcionándole ofrendas. En el mito teogónico, los dioses son descritos como criaturas ingenuas, que necesitan acumular experiencia para aprender la manera correcta de alimentarse y poder prosperar. No son presentados como entidades todopoderosas, sino como seres frágiles, casi torpes. K'akoch les dona el maíz, para que puedan sustentarse, y éstos aprenden a preparar el grano tras un largo proceso de ensayos, convirtiéndolo en una sustancia comestible y agradable (Bruce 1974: 35-42).

Del mismo modo, los dioses principales: Hachäkyum (Nuestro Verdadero Padre) y U Lak a Hachäkyum (Nuestra Verdadera Madre) crearon a los lacandones, otorgándoles el maíz y todas las herramientas para prepararlo. Este primer paralelismo permite introducir un punto fundamental: las deidades son veneradas y respetadas por los humanos en cualidad de creadores del cosmos; pero los informantes subrayan que ellos, en el espacio celeste o en el inframundo, se asemejan en todo a los lacandones. Se dice que las deidades masculinas poseen milpas, trabajan en los campos, cazan en la selva; las diosas trabajan en la cocina, preparan tortillas para sus esposos, tejen y cuidan a sus hijos. Así como los lacandones veneran a sus creadores, las deidades poseen templos en los que se rinde culto a K'akoch, en honor al cual se prepara ba'alché3 ${ }^{3}$ se ofician largas

\footnotetext{
3 Bebida alcohólica ceremonial de origen prehispánico, usada entre los mayas de la península de Yucatán y los mayas lacandones en rituales religiosos y curativos; se obtiene de la
} 
Alice Balsanelli, La comida del otro: el papel del régimen alimenticio en la formación de identidad y alteridad entre los mayas lacandones, perifèria 22(2), diciembre 2017

revistes.uab.cat/periferia

ceremonias, se canta y se toca música. Igualmente, la estructura de la familia divina y la familia de las deidades ctónicas refleja el patrón de asentamiento patriuxorilocal lacandón (Marion 1999).

También, por lo que respecta a la apariencia, los seres divinos son descritos por los informantes como parecidos a los lacandones. Es interesante notar la distinción que se hace entre el creador de los Jach Winik, Hachäkyum, y Äkyantho, el dios de los ladinos y de los extranjeros: el primero es descrito como un to'ohil (hombre sabio), que lleva puesta la túnica y anda descalzo, su cabello es largo y es de tez morena, ama cazar en la selva, fumar puros y le gusta tomar ba'alché. Por el contrario, Äkyantho' es de piel blanca, posee mucho dinero y máquinas, lleva camisa, pantalón, botas y sabe usar muchas herramientas desconocidas a los dioses lacandones: caza con armas de fuego y sabe manejar los carros. Asimismo, el carácter de las deidades las acerca a las personas comunes: raras veces son descritas como seres perfectos o infalibles; por lo general, se presentan como personas vulnerables, irascibles, celosas, caprichosas. El paralelismo entre dioses y humanos que hasta aquí hemos evidenciado nos permite entender la razón por la cual los lacandones afirman que los dioses son winik (gente).

Cuando se les pregunta sobre las diferencias entre las deidades y los humanos, los informantes recurren a la descripción de los hábitos alimenticios de los primeros. Por lo general, los dioses se alimentan de esencias, mientras que los humanos se nutren de sustancias; como lo reporta Boremanse, ellos se alimentan de «el doble invisible de las ofrendas» (2006: 20). Reportamos un mito, relatado por la informante Koj, la cual explica de qué manera se alimenta un dios lacandón:

Un día llega el dios Hachäkyum a una milpa, estaba hambriento de tanto caminar, allí estaba un lacandón muy pobre, no tenía nada que comer, sólo un calabazo lleno de pozol ${ }^{4}$. El dios le dice: "Estoy hambriento, ¿me puedes

fermentación de la corteza de un árbol (Lonchocarpus longistylus) y se endulza con azúcar o miel silvestre.

${ }^{4}$ Bebida refrescante a base de maíz. 
Alice Balsanelli, La comida del otro: el papel del régimen alimenticio en la formación de identidad y alteridad entre los mayas lacandones, perifèria 22(2), diciembre 2017

\section{$\underline{\text { revistes.uab.cat/periferia }}$}

dar de comer?". El hombre estaba preocupado, porque sólo su pozolito tenía, pero era un buen hombre y se lo dio al dios. Hachäkyum empezó a tomar y el Jach Winik estaba preocupado; pensaba: "iAy!, ¿qué comeré hoy?" El dios se fue contento y el campesino entonces miró la olla: iEstaba llena! Y eso porque el dios sólo se había tomado el alma del pozol, mientras que su cuerpo había quedado en el calabazo, para que el hombre comiera también. Estuvo muy feliz Hachäkyum y a ese campesino le dio muchas buenas cosechas, ya no padeció hambre. A otro lacandón que fue egoísta, que no le dio de comer al dios, sólo desgracia le cayó: le había dicho a Hachäkyum "Busca en otro lado tu comida, porque yo no tengo", pero también tenía su pozol guardado. Ese ya no volvió a cosechar maíz, casi murió de hambre.

Esta idea está presente entre los antiguos mayas, como lo apunta Taube en un estudio sobre las características de los quemadores de incienso: «Los incensarios son los fogones de cocina para dioses y ancestros» (2009 [1998]:16). De hecho, la mayoría de las ofrendas eran quemadas para que su esencia pudiera llegar a los seres celestes bajo la forma de humo (Nájera 2004: 15). El uso de los quemadores de incienso es una de las prácticas prehispánicas que los lacandones han mantenido a lo largo del tiempo: se trata de incensarios de arcilla, que representan el rostro de las deidades del panteón y presentan la cavidad oral en la que se suministran las ofrendas. Una de las principales es la resina de $\operatorname{copal}^{5}$, que es quemada al interior de los braseros. El copal crudo es Ilamado u sakän a kuj ("la masa de los dioses"), se piensa que es masa de maíz que, una vez quemada, sube al cielo en la forma de humo. De hecho, los braseros sagrados son llamados u läk'i kuj ("los platos de los dioses"); opinamos que esta expresión indica que los braseros son los platos sobre los que se sirve la comida de las deidades (el copal). Un sabio de la comunidad de Najá afirmó lo siguiente:

\footnotetext{
${ }^{5}$ Resina aromática vegetal que se extrae de varios tipos de árboles, en particular del árbol Bursera Excelsa.
} 
Alice Balsanelli, La comida del otro: el papel del régimen alimenticio en la formación de identidad y alteridad entre los mayas lacandones, perifèria 22(2), diciembre 2017

\section{$\underline{\text { revistes.uab.cat/periferia }}$}

Esta es la masa de los dioses, aún está cruda, cuando se la das y la quemas [sobre el incensario] es su tortilla. Los dioses comen tortilla como nosotros, pero tú ves copal fresco y luego ves humo de copal, pero es su comida de Hachäkyum, de K'änänk'ax [el que cuida a la selva], de Nuestra Madre, su Señora de Hachäkyum, de su yerno Ah K'in Ch'ob (Chan K'in Antonio).

Todos los autores que han analizado los ritos lacandones subrayan que las ofrendas deben ser interpretadas en un sentido metafórico: se proporciona achiote ${ }^{6}$ en lugar de sangre humana, las figurillas antropomorfas de látex ${ }^{7}$ sustituyen a las víctimas sacrificiales, los tamales pueden simbolizar una ofrenda de carne humana o animal (Mc Gee 1989). Mc Gee afirma que las ofrendas Ilegan al cielo bajo una forma inversa: el humo del incienso se convierte en tortillas, una pequeña cantidad de ba'alché amargo se convierte en una gran cantidad de ba'alché dulce, las hojas de palma sobre las cuales se ponen las ofrendas se convierten en asientos de madera parecidos a los que utilizan los hombres lacandones en el templo. El autor acude al concepto de reversal form, para expresar esta "transformación" que pasa entre la tierra y el cielo (ibíd.: 107). Sin embargo, los informantes expresan con claridad que no se trata de una transformación: lo que los humanos ven como una pequeña cantidad de comida es un banquete a los ojos de los dioses y el humo del copal quemado en los braseros es tortilla en el plano celeste:

Tienes tus incensarios. A ellos háblales. Solamente a tus incensarios les hables. Les das copal. Háblales y te escucharán. Llama a tus incensarios. Les das a tus incensarios copal como su alimento. Los dioses se alimentan de tus palabras. Lo ves, pero no lo ves. A ti te parecerá como copal, pero no es copal (Bruce 1974: 215).

\footnotetext{
6 Bixa Orellana, especia de color rojizo de la semilla del arbusto homónimo, su color y consistencia recuerdan a la sangre.

7 En los ritos se queman figuras antropomorfas hechas de látex natural; se piensa que, una vez quemadas, éstas se convierten en muchachos que trabajan en las milpas de los dioses.
} 
Alice Balsanelli, La comida del otro: el papel del régimen alimenticio en la formación de identidad y alteridad entre los mayas lacandones, perifèria 22(2), diciembre 2017

\section{revistes.uab.cat/periferia}

Una informante de Najá explicó que, si se ofreciera una gran cantidad de comida a los dioses, para ellos sería un gran insulto, porque: «Lo que para nosotros es mucho, para ellos es poquito, mientras lo que para nosotros es poco, para ellos es mucho». Sin este juego de perspectivas, el intercambio que tiene lugar en el templo entre los humanos y el dios no sería equitativo: pocas ofrendas a cambio de un año de buena cosecha, una pequeña cantidad de ba'alché a cambio de la curación de un enfermo. No obstante, no se trata únicamente de un recurso conceptual que permite equilibrar el balance entre las ofrendas y los beneficios obtenidos, esta concepción atañe a la perspectiva distinta que caracteriza la otredad. Los distintos hábitos alimenticios revelan los límites de la "humanidad compartida o extendida" en los sistemas animistas.

\section{Comer como dios, comer como humano}

Fausto afirma que "comer como el otro" permite la identificación con la alteridad (2002: 15). De acuerdo con el pensamiento indígena, una vez ingerido, el alimento entra a formar parte del organismo, tanto que el acto de consumir "la comida del otro" puede provocar un cambio ontológico. Esta idea fue evidenciada por LéviBruhl, quien proporciona interesantes elementos para nuestros análisis:

Casi nunca los primitivos aceptan de entrada los alimentos desconocidos o aun conocidos, ofrecidos por los extranjeros [...] comer, no es para él solamente satisfacer una necesidad elemental. Es un acto cuya significación y consecuencias místicas pueden ser de una importancia capital. La sustancia del alimento se incorpora a la del hombre que la consume; la participación es tan íntima, que las dos sustancias forman un todo. Lo que come el primitivo forma parte de su yo (1972: 336).

Una creencia relatada por Spencer señala muy bien cuáles pueden ser las consecuencias de la introducción de un alimento nuevo en su régimen: "La existencia de mestizos, en muchas tribus de Australia del Norte, ha sido al principio universalmente explicada por sus madres de la manera siguiente: 
Alice Balsanelli, La comida del otro: el papel del régimen alimenticio en la formación de identidad y alteridad entre los mayas lacandones, perifèria 22(2), diciembre 2017

\section{revistes.uab.cat/periferia}

"Yo comí demasiada harina del hombre blanco". La diferencia esencial, para ellos, entre su vida antes de entrar en contacto con los blancos y después, no estaba en las relaciones sexuales que mantenían con ellos, sino en haber comido harina blanca, lo que naturalmente afectó el color de su descendencia" (Spencer, Native tribes of the Northern territory of Australia, ibíd.: 337).

Si bien las concepciones reportadas se podían explicar con relación a una falta de conocimiento científico por parte de los indígenas, como bien lo apunta Lévi-Bruhl, éstos creían que las sustancias ingeridas podían provocar una modificación en sus cuerpos; por ello, el proceso de mestizaje se explica como el resultado de la ingestión del "alimento extraño". En este sentido, la modificación en el color de los niños no se debe al mestizaje, a "los genes de los blancos", diríamos nosotros, sino al color blanco de la harina.

Por lo que respecta al caso lacandón, en el presente apartado se recurrirá al mito para aclarar la manera en que el régimen alimenticio puede permitir un proceso de transformación ontológica: un cambio de alimentación puede implicar un cambio de cuerpo. Empezaremos con el análisis de un mito: El niño adoptado por los dioses. Después de haberse vuelto a casar, una viuda decide liberarse del niño que tuvo de su primer esposo, en tanto lo considera una molestia. Junto con el nuevo esposo, abandona al pequeño en una milpa; allí es rescatado por el dios Ah K'in Chob y es llevado al cielo. Tras unos días, el padrastro, atormentado por el remordimiento, decide volver al campo para buscar al hijastro, pero éste había desaparecido. Entonces, preocupado por el niño, decide visitar a Haaw, el sabio lacandón que habla con los dioses, el cual le dice:

[...] él no está aquí [...] además, vosotros lo habéis rechazado, abandonado, extraviado. Su madre no quería nada con él. Ahora no tenéis más al niño. Nuestro Señor lo ha tomado. Él está con ellos en el presente y para siempre; ya que él se ha convertido en inmortal. Yo, veo a los dioses, pero soy mortal porque no como de su alimento; pero tu hijastro se ha convertido en dios. Los 
Alice Balsanelli, La comida del otro: el papel del régimen alimenticio en la formación de identidad y alteridad entre los mayas lacandones, perifèria 22(2), diciembre 2017

\section{$\underline{\text { revistes.uab.cat/periferia }}$}

dioses lo han adoptado como uno de los suyos. Crecerá entre ellos (Boremanse 2006: 191).

El niño, tras haber consumido el alimento de los dioses, había sido asimilado por el colectivo divino. Los lacandones piensan que los dioses se nutren de "maíz húmedo" (de tortillas no cocidas, hechas con maíz azul o negro), un alimento divino que en el mundo terrenal tiene la apariencia de copal (ibíd.: 647). Se piensa que los seres humanos no pueden distinguir entre la tortilla cocida (el alimento de los hombres) y la tortilla de los dioses, como se aclarará en el siguiente mito. El hombre que consume el maíz divino se volverá ligero y volará al cielo de los dioses, sin poder regresar a su morada terrenal.

En el segundo mito, Nuestro Antepasado arrebatado por los Wayantekob ${ }^{8}$ (ibíd.: 329-335), encontramos una situación parecida: después de que su madre se enferma, el joven $\mathrm{K}^{\prime}$ in decide ir a la selva a recolectar resina de copal para ofrendarla a los dioses. En el bosque encuentra a un Wayantekob, el cual le asegura que curará a su madre. A cambio, le pide al muchacho que suba al cielo junto con él. K'in rechaza la oferta y contesta que quiere volver con su madre para poderla cuidar; entonces, el dios le ofrece dos tortillas: una de maíz verdadero y otra hecha con el maíz húmedo. El chico no puede ver la diferencia, ya que para él las dos tortillas son idénticas, y escoge la tortilla de los dioses, comiéndose un cachito. Su cuerpo se vuelve ligero y el Wayantekob le advierte que no podrá regresar a su casa y que jamás habría vuelto a ver a su madre. K'in sube al cielo y, después de unos días, sus familiares empiezan a preocuparse; su hermano decide quemar figurillas de hule para enviarlas como mensajeros hasta la vivienda del verdadero padre, Ik Chan Yum ${ }^{9}$. El Dios envía a su hijo T'up con los Wayantekob, para ordenarles que devuelvan al joven lacandón a sus parientes; tras una pelea entre deidades, los Wayantekob aceptan devolver al muchacho y T'up lo acompaña hasta la casa de su madre. Pasado un tiempo, los Wayantekob vuelven a buscar a

\footnotetext{
8 Dioses-jaguar que viajan entre la tierra y el cielo.

9 Otro nombre de Hachäkyum.
} 
Alice Balsanelli, La comida del otro: el papel del régimen alimenticio en la formación de identidad y alteridad entre los mayas lacandones, perifèria 22(2), diciembre 2017

\section{$\underline{\text { revistes.uab.cat/periferia }}$}

$K^{\prime}$ in en la tierra, donde se dan cuenta que el cuerpo del joven se había vuelto muy pesado; entonces, lo cuelgan de las ramas de una ceiba y empiezan a pegarle para que se desangre. Lo golpean duramente, repitiendo que el chico está demasiado pesado, hasta dejarlo inconsciente. Los dioses-jaguar lo despiertan y lo llevan a la casa de su madre para que pueda vomitar en una olla. El pobre muchacho vomita mucha sangre, pero los dioses-jaguar quieren averiguar si su cuerpo sigue pesado. Lo vuelven a colgar de la ceiba y de ahí lo avientan, dejando caer al mismo tiempo una hoja del árbol, para ver si son igual de ligeros. Pero el chico es más pesado que la hoja y cae rápidamente, así que los Wayantekob vuelven a pegarle para aligerarlo. Cuando el joven pierde casi la totalidad de su sangre, lo someten a la misma prueba. Finalmente, $K^{\prime}$ in resulta ser tan ligero como una hoja de ceiba. Esto le permite subir una última vez al cielo para ver a los dioses y después se le otorga el permiso de vivir junto a su familia.

Según mi interpretación, el protagonista del mito, que había permanecido entre los dioses mucho tiempo, alimentándose de la comida divina, había sufrido una transformación corporal (cuyo índice es la "ligereza" que se menciona a lo largo de la narración). Por esta razón, para poderse quedar en la tierra, tuvo que volverse "pesado" otra vez, alimentándose de comida humana. Cuando los Wayantekob quisieron llevarlo otra vez al cielo, tuvieron que depurar el muchacho de la pesadez adquirida a través de los alimentos humanos, a través del desangramiento (recordemos que la comida es asimilada por medio de la sangre) y vomitando en la olla.

Bormanse (2006) postula que los lacandones conectan el concepto de "pesado" con el de "pecado": quedándose en la tierra, el muchacho había vuelto a ser un mortal; dado que la condición de pecadores caracteriza a la especie humana, los Wayantekob tuvieron que desangrarlo para liberarlo del pecado. El autor invita a revisar otro mito en el que se cuenta por qué el dios Sukunkyum se quedó en el inframundo, mientras que las demás deidades subieron a la superficie o al cielo (ibíd.: 289-290). Según los lacandones del sur, los seres humanos vivían originariamente en el inframundo, junto con algunas deidades. Los Jach Winik salieron de un agujero y empezaron a poblar la tierra, pero el dios Sukunkyum tuvo 
Alice Balsanelli, La comida del otro: el papel del régimen alimenticio en la formación de identidad y alteridad entre los mayas lacandones, perifèria 22(2), diciembre 2017

\section{$\underline{\text { revistes.uab.cat/periferia }}$}

que quedarse en cuanto «comió carne humana, de esta manera se puso muy pesado y no pudo elevarse hasta este mundo» (ibíd.:290). Los demás dioses, que se alimentaban de presas de cacería, pudieron salir a la superficie junto con los humanos; también el Sol comió carne humana, por esta razón su cuerpo se volvió pesado y cada día llega al cenit lentamente, tras salir del inframundo. Según Boremanse, la pesadez de Sukunkyum y del Sol es debida al pecado cometido por haber comido carne humana. Opinamos que no se trata de una cuestión de falta moral, concepto puramente cristiano: los demás dioses compartieron la comida de los lacandones, alimentándose de presas de cacería y fueron a vivir con ellos en la tierra. El hecho de que Sukunkyum se alimentara de carne humana lo convirtió en una "otredad", algo impuro, peligroso, que tuvo que ser confinado bajo la tierra. El mismo destino le tocó al Sol, el cual es destinado a bajar al inframundo cada noche para alimentarse en la casa de Sukunkyum.

Analizando el caso de Sukunkyum y del Sol, podríamos preguntarnos cómo unos seres antropófagos se convirtieron en el protector de los humanos en el inframundo y en la deidad solar. La respuesta se encuentra en otro mito, El hombre que atrapaba a los topos (ibíd.:69). El Inframundo lacandón se divide en dos partes: la morada de Sukunkyum y la de Kisin ("El Causante de la Muerte"). El primero es el que juzga a las almas que llegan al más allá, se dice que es benévolo hacia los lacandones, así como lo es su esposa. El segundo desempeña la labor de torturar a las almas de los finados que llegan al Metlan, la parte del inframundo que él rige. Los primeros, para convertirse en los protectores de los lacandones, tuvieron que aprender a comer la verdadera comida, mientras que los Kisin se nutren de carne humana podrida, hongos de árbol, larvas y gusanos (Bruce 1974: 101). Sukunkyum y su esposa, alimentándose de la verdadera comida, adquirieron el punto de vista de los humanos: ellos ven almas donde Kisin mira presas de cacería. En una parte del mito, la esposa de Sukunkyum, llamada X-Nuk, instruye a la hija de Kisin sobre la comida de los seres humanos, para que la muchacha pueda casarse con uno de ellos, y la invita a probar una galleta de maíz:

"iOh, esto es delicioso!". Dijo la hija de Kisin. 
Alice Balsanelli, La comida del otro: el papel del régimen alimenticio en la formación de identidad y alteridad entre los mayas lacandones, perifèria 22(2), diciembre 2017

\section{$\underline{\text { revistes.uab.cat/periferia }}$}

"iOh sí!" Dijo Nuestra Madre, "Sukunkyum no come hongos de árbol. iTú y los tuyos sí los coméis!"

"iNo, X-Nuk, son tortillas, no son hongos!".

"iEsos son hongos! Y vosotros no coméis frijoles..."

"Sí, X-Nuk, inosotros comemos frijoles!"

"¿Cuáles frijoles?", dijo la esposa de Sukunkyum. "iVosotros coméis larvas de moscas verdes!"

"No, X-Nuk. iNo!", dijo la hija de Kisin.

"iY coméis los cuerpos putrefactos de mis hijos!", dijo Nuestra Madre.

Ella estaba furiosa. Los Kisin comen los cadáveres en descomposición y beben

el jugo de la putrefacción; este es su atole de maíz (Boremanse 2006: 81).

De hecho, se especifica que la hija de Kisin, para poderse casar con el hombre lacandón que deseaba, tuvo que ser incorporada al grupo de los humanos aprendiendo a cocinar y a consumir los alimentos lacandones: «La hija de Kisin venía frecuentemente a visitar a la esposa de Sukunkyum y ésta la hacía trabajar. Le enseñó a comer tortillas y ella perdió la costumbre de comer hongos arborícolas, ya que le daban tortillas de maíz» (ibíd.).

Volviendo al análisis de los mitos, me atrevo entonces a proporcionar otra interpretación de los conceptos de "ligereza" y "pesadez": esta idea no tiene que ver con una cuestión de faltas morales, sino los seres que comen la comida que se consume en otro colectivo terminan identificándose con los miembros de éste. Lo que ocurre es un cambio de cuerpos, ya que el alma permanece inalterada: de dioses se pasa a ser humanos, de humanos a dioses.

\section{Comer lo podrido: la alimentación en el inframundo}

En la literatura maya, encontramos numerosos mitos que narran la bajada al inframundo de algún ancestro, el cual, al contacto con las deidades ctónicas, se 
Alice Balsanelli, La comida del otro: el papel del régimen alimenticio en la formación de identidad y alteridad entre los mayas lacandones, perifèria 22(2), diciembre 2017

\section{$\underline{\text { revistes.uab.cat/periferia }}$}

entera de que éstas se caracterizan por alimentarse de sustancias podridas y hediondas. Las descripciones del bajo mundo reflejan las características de los alimentos que ahí se consumen: se trata de un plano oscuro y peligroso, asociado con elementos "fríos", que subrayan el carácter no-humano de sus moradores (Alcántara 2003:192). En muchas narrativas mayas encontramos la descripción de los alimentos ofrecidos a los humanos que se atrevieron a superar la barrera que separa el mundo de los vivos del de los muertos. Proporcionaremos algunos ejemplos, empezando por un relato de los mayas tzotziles: «Ahora voy a probar mis platillos favoritos". iLejos estaba de imaginar lo que era la comida! Primeramente, le sirvieron orina por café; huevecillos de mosca para arroz, y tortillas de excremento de animales [...] eso era lo que se comía en la otra vida» (ibíd.: 197). En un mito tojolabal, se relata la bajada al inframundo de un hombre que es invitado por "El Dueño" a probar los alimentos que se consumen en su reino: «[...] se le ofreció un molcajete de frijoles, una taza de pozol y "carnita seca tasajeada" que no pudo probar, pues descubrió que eran puras "garrapatas cocidas", "pus de animales"» (ibíd.: 202). En un relato tzeltal, se cuenta cómo un hombre pudo conocer el más allá tras haber encontrado a un misterioso caballero ladino montado en un caballo negro, que lo acompañó al bajo mundo. Allí el personaje misterioso le pidió al tzeltal que fuera a buscar leña para el fuego, pero el ancestro se dio cuenta que ese "demonio" utilizaba huesos humanos en lugar de madera (Guzmán 1985: 279). De hecho, en los Altos de Chiapas, otra manera de llamarle al inframundo es Kajktimb'ak, literalmente "calentar con huesos" y en muchos relatos se especifica que lo que los vivos ven como despojos de seres humanos serían en realidad la leña de los moradores del bajo mundo (Guiteras 1986).

En la narrativa lacandona, es Nuxi el ancestro que baja al Metlan y regresa con vida a la selva para contar sus vivencias a sus compañeros (Bruce 1974; Boremanse 1998, 2006). Se trata de un cazador que, tras haber exterminado a muchos topos, es hechizado por la bella hija de Kisin, protectora de dichos animales. La muchacha lo invita a seguirla hasta el reino de su padre, donde aprende las costumbres alimenticias de los "demonios". Cuando Nuxi baja al inframundo, se le ofrecen 
Alice Balsanelli, La comida del otro: el papel del régimen alimenticio en la formación de identidad y alteridad entre los mayas lacandones, perifèria 22(2), diciembre 2017

\section{$\underline{\text { revistes.uab.cat/periferia }}$}

varios tipos de alimentos, que a los ojos de los Kisin son tortillas, frijoles y atole, pero que, en realidad, son cadáveres putrefactos, moscas y larvas (Boremanse 2006:84). En palabras de una informante: «La leña del fuego era el esqueleto, para ellos lo que es leña es hueso, nuestros huesos, y lo que es frijol era mosca, era pura mosca, salió volando. $\mathrm{Y}$ el chile era puro gusano y la tortilla era carne podrida».

Sin embargo, el Causante de la Muerte se nutre también y, sobre todo, de almas humanas. En la selva del inframundo están presentes unos monos, que son el doble de las almas de los humanos. En el mito, se aclara que esos animales no pueden ser matados o consumidos, en cuanto son esencias anímicas; no obstante, Kisin los ve como presas, puede cazarlos y alimentarse de su carne. También en este caso encontramos una diferencia de perspectivas entre la esposa de Sukunkyum y el Causante de la Muerte, que intercambian el siguiente diálogo:

Kisin, al regresar de la caza, decía a la esposa de Sukunkyum: "iHe matado a un mono, X-Nuk!" "iCómo!", respondía ella. "Esta no es carne que tú puedas comer, es el doble del alma de uno de mis hijos". "iNo, X-Nuk!" contestaba Kisin. "iEs un animal de caza, es un mono!" (Boremanse 2006: 76).

El punto de vista de Kisin, que representa la antítesis a lo humano, es distinto al de X-Nuk, que es la protectora de los Jach Winik y que, como hemos visto, se alimenta de la misma comida que comen los hombres. $\square$ Es evidente que, a los ojos de Kisin, el alma es carne, cuando en realidad es una esencia inmaterial; asimismo, en la tierra de los vivos, Kisin posee la facultad de extraer las almas humanas para alimentarse de ellas; se dice: a Kisin ku chi a pixän, "Kisin te come el alma", como también lo han observado Marion (1999) y Bruce (1971).

Con respecto al caso amazónico, Viveiros de Castro apunta que los espíritus representan la alteridad depredadora por excelencia (2010:14). En sus estudios sobre la sociedad makuna, Arhem evidencia que en la categoría "depredadores supremos" los indígenas incluyen a los jaguares, las anacondas, las principales aves rapaces y los espíritus; sin embargo, mientras los animales se alimentan de carne humana, los espíritus y algunos dioses devoran almas. Así, subraya que las 
Alice Balsanelli, La comida del otro: el papel del régimen alimenticio en la formación de identidad y alteridad entre los mayas lacandones, perifèria 22(2), diciembre 2017

\section{revistes.uab.cat/periferia}

relaciones entre los miembros de los distintos colectivos se basan en una cadena alimenticia: «Tal como el cazador mata y consume a su presa, las divinidades capturan y devoran humanos» (2001: 273).

Todos los mayas contemporáneos piensan que el alma humana (o una de ellas) posee la facultad de abandonar el organismo en situaciones extraordinarias (durante experiencias oníricas, en caso de embriaguez, consumo de sustancias psicoactivas). Cuando la esencia anímica se priva de la protección del cuerpo, puede ser secuestrada o comida por entidades no-humanas, provocando la muerte de la víctima o, en casos menos graves, causando alguna enfermedad.

También las almas de los difuntos se nutren de la esencia etérea de los alimentos, que son proporcionados como ofrendas por los vivos. Entre los mayas yucatecos, en Día de Muertos se celebra el Hanal Pixan, "La comida de las almas", cuando se piensa que las almas de los finados bajan a la tierra para comer lo que sus seres queridos han dejado en los altares. Sin embargo, los alimentos quedan intactos, en cuanto los pixan'ob (alma en plural) se nutren únicamente de la esencia de las cosas:

Una de las finalidades de los rituales para los muertos, como para la mayoría de las entidades sobrenaturales del panteón maya, es alimentar las almas entregándoles la esencia (inmaterial) de los alimentos (se habla también de su -huy, literalmente lo "puro" de las ofrendas, para insistir en su carácter intacto) (Le Guen 2008:89).

Mientras que en muchos grupos mayas la comida destinada a los difuntos puede ser posteriormente consumida por los seres humanos, los lacandones piensan que ésta se vuelve incomestible, tras haber perdido "su espíritu". A este propósito, proporcionaremos un ejemplo etnográfico: Chanuk explica la manera en que las almas de los difuntos se alimentan de las ofrendas. La mujer sentía que su vivienda era visitada por un pixän (alma) errante y ella advertía que se trataba de un espíritu hambriento: 
Alice Balsanelli, La comida del otro: el papel del régimen alimenticio en la formación de identidad y alteridad entre los mayas lacandones, perifèria 22(2), diciembre 2017

\section{revistes.uab.cat/periferia}

El alma quería comer, ne guik [muy hambrienta], hazte cuenta que es winik, también quiere su comida; las almas que se quedan piden comida, por ejemplo, éste [la que la visitaba], ¿por qué no fue al cielo? Creo no lo enterraron bien o si uno muere y nadie se entera, el alma se queda. La comida del muerto es u pixän yochi [el alma de la comida]. Bueno, yo dejé mi tortillita aquí y le dije "iCome! Es para ti", en la mañana lo ves que sigue, porque si fuera ratón ya le ves sus huequitos. No, yo sabía que era alma. Entonces, en la mañana encuentro mi tortilla enterita, pero no pienses que no comió: sí, comió, pero tú no lo ves, como en el templo con las ofrendas. Bien, no lo ves, porque se comió u pixän waj [su alma de la tortilla] y luego ya la tortilla no sirve, tú no la puedes comer, si la comes te enfermas o te mueres, ya es comida de los muertos, no es para ti.

Chanuk menciona que las almas son "gente", pero se distinguen de la Verdadera Gente por su alimentación. De acuerdo con el testimonio, la tortilla pierde su alma en el momento en que la entidad extrahumana la absorbe, entonces se vuelve un alimento peligroso para los seres humanos. Por lo general, los alimentos que se ofrendan en el templo pueden ser consumidos por los seres humanos terminando el ritual, mientras que las ofrendas para los muertos se dejan pudrir en las tumbas. No disponemos de los datos suficientes para explicar la razón de esta diferenciación; quizás ésta se encuentra en la actitud diferente que los lacandones mantienen con respecto a las deidades y a los difuntos: los primeros son generalmente considerados como seres benévolos, siempre y cuando se mantenga una buena relación con ellos, y pertenecen a una categoría bien definida: son dioses. Por el contrario, las almas de los difuntos son seres liminales, que oscilan entre el mundo terrenal y la muerte, sobre todo aquellas que pertenecen a sujetos que no han recibido un entierro apropiado y que se quedaron atrapadas entre los vivos. Su condición liminal es lo que las vuelve peligrosas, aunque se trate del espíritu de un ser querido o un familiar, ya que pertenecen a una categoría ambigua: no poseen un cuerpo, no pertenecen al mundo de los vivos, pero en éste se mueven e intentan interactuar con los lacandones. Por esta razón, opino que los 
Alice Balsanelli, La comida del otro: el papel del régimen alimenticio en la formación de identidad y alteridad entre los mayas lacandones, perifèria 22(2), diciembre 2017

revistes.uab.cat/periferia

alimentos que ellos tocan se vuelven impuros y pueden contaminar el cuerpo humano.

\section{Conclusiones}

La alteridad lacandona abarca distintas categorías de seres con los cuales los indígenas comparten el ambiente silvestre e interactúan constantemente. Todos los existentes del cosmos animista poseen un alma y son susceptibles de ser personas (winik) al interior de los respectivos colectivos de pertenencia. Estamos ante una condición de humanidad generalizada $y$, en ausencia de una clasificación taxonómica dictada por parámetros científicos, los Jach Winik recurren al régimen alimentario para distinguir la Verdadera Gente de todas las demás subjetividades que los rodean. En este sentido, se definen como grupo étnico cuando tienen que confrontarse con una alteridad humana (mestizos, otros grupos indígenas, blancos), afirmando ser los únicos Hombres Auténticos que se alimentan de la "verdadera comida" (el maíz y los demás productos silvestres que caracterizan su dieta).

Cuando tienen que diferenciarse de la alteridad no-humana o, mejor dicho, "potencialmente humana" -que abarca dioses, seres del inframundo y espíritusvuelven a emplear la alimentación como parámetro de discriminación ontológica. La comida y el cuerpo están estrechamente relacionados, ya que las sustancias ingeridas son parte integrante del organismo y lo constituyen; por consiguiente, es posible crear lazos de parentesco (un mismo cuerpo) a través de la comensalidad o provocar un cambio ontológico al alimentarse de la comida consumida en otro colectivo. Los informantes argumentan que los alimentos están sujetos a un juego de perspectivas: todos los existentes piensan de buena fe alimentarse de maíz y alimentos cocidos - una consecuencia del hecho de que todos comparten la misma alma y la misma cultura-, cuando en realidad consumen esencias, almas, carne cruda o humana. En el marco de una ontología animista, sin el recurso de este juego de miradas, nada distinguiría formalmente a un lacandón de los seres que lo rodean. 
Alice Balsanelli, La comida del otro: el papel del régimen alimenticio en la formación de identidad y alteridad entre los mayas lacandones, perifèria 22(2), diciembre 2017

revistes.uab.cat/periferia

\section{Bibliografía}

Alcántara, R. B. (2003). Comer lo que hiede. Alimentos del 'otro mundo' según algunos relatos mayas. Estudios de Cultura Maya, XXIV, 197-219.

Airhem, K. (2001). Ecocosmología y chamanismo en el Amazonas: variaciones sobre un tema. Revista Colombiana de Antropología, 37, 268-288.

Boremanse, D. (1998). Hach Winik, The Lacandon Maya of Chiapas, Southern Mexico. New York: Institute of Mesoamerican Studies, The University at Albany Press.

- (2006). Cuentos y Mitología de los Lacandones, Contribución al estudio de la tradición oral maya. Guatemala: Academia de Geografía e Historia de Guatemala.

Bruce, R. S. (1971). Los Lacandones: Cosmovisión Maya. Proyecto de Estudios Antropológicos del Sureste. México: Instituto Nacional de Antropología e Historia.

- (1974). El Libro de Chan Kin. México: Instituto Nacional de Antropología e Historia.

Descola, P. (2012). Más allá de naturaleza y cultura. Buenos Aires: Amorrotu Editores.

Fausto, C. (2002). Banquete de gente: comensalidade e canibalismo na Amazonia. Mana 8(2), 7-44.

Fischler, C. (1995) El (h)omnívoro, El gusto, la cocina y el cuerpo. Barcelona: Editorial Anagrama.

Grotti, E., Brightman, M. (2012). Humanity, Personhood and Transformability in Northern Amazonia. In Animism in rainforest and tundra: personhood, animals, plants and things in contemporary Amazonia and Siberia (pp. 162174), United States: Berghahn Books. 
Alice Balsanelli, La comida del otro: el papel del régimen alimenticio en la formación de identidad y alteridad entre los mayas lacandones, perifèria 22(2), diciembre 2017

\section{revistes.uab.cat/periferia}

Guiteras, H. C. (1986). Los peligros del alma, Visión del mundo de un tzotzil. México:FCE.

Guzmán, A. (1985). Una leyenda tzeltal: el infierno o k'atimbak (calentar con huesos). Tlalocan, 10, 257-272.

Le Guen, O. (2008). Ubéel pixan: el camino de las almas. Ancestros familiares y colectivos entre los mayas yucatecos. Península, III (1), 83-120.

Lévi-Bruhl, L. (1972). La mentalidad primitiva. Buenos Aires: Editorial la Pleyade.

Marion S., M.O (1999). El Poder de las Hijas de Luna. México: Plaza y Valdés.

Mc Gee, R. J. (1989). Life, Ritual, and Religion among the Lacandon Maya. Belmont, California: Wadsworth Publishing Company.

Nájera, C. M. I. (2004). Del mito al ritual. Revista Digital Universitaria, 5 (6): 1-18.

Ruz, M. H. (1981). Los Hombres Legítimos, Aproximación antropológica al grupo tojolabal, Volumen I. México: UNAM, Instituto de Investigaciones Filológicas, Centro de Estudios Mayas.

Taube, K. A. (2009) Traducción de The Womb of the World (1998): The Cuauhxicalli and Other Offering Bowls of Ancient and Contemporary Mesoamerica. Maya Archaeology 1, 86-106; San Francisco: Precolumbia Mesoweb Press. www.mesoweb.com/es/ articulos/Taube/Cuauhxicalli.pdf.

Trench, T. (2005). Representaciones y sus impactos: el caso de los lacandones en la Selva Lacandona. Liminar, Estudios Sociales y Humanísticos, 3, (2), UNICACH, San Cristóbal de las Casas, Chiapas, 48-69.

Vilaça, A. (2016). Praying and preying. Christianity in indigenous Amazonia. California: University of California Press.

Viveiros de Castro, E. (2010). Metafisicas Caníbales, Líneas de antropología postestructural, Buenos Aires: Katz Editores. 